\title{
Resources and Pilot Results for Establishing a Mongolian Twin Register
}

\author{
Bayasgalan Gombojav, ${ }^{1,9}$ Otgonbayar Damdinbazar, ${ }^{2,9}$ Narandalai Danshiitsoodol, ${ }^{3,9}$ \\ Gonchigsuren Dagvasumberel, ${ }^{6,9}$ Erkhembulgan Purevdorj, ${ }^{8}$ Enkhtsetseg Gombojav, ${ }^{9}$ \\ Urjinbadam Chuluunbaatar, ${ }^{4}$ Chimedsuren Ochir, ${ }^{5}$ Purevdorj Ichinkhorloo, ${ }^{7,9}$ and Joohon Sung ${ }^{10}$ \\ ${ }^{1}$ Institute of Environment and Health, School of Public Health, Seoul National University, Seoul, Korea \\ ${ }^{2}$ Division of Educational Policy and Management, Health Sciences University of Mongolia, Ulaanbaatar, Mongolia \\ ${ }^{3}$ Medical Faculty, Graduate School of Biomedical and Health Sciences, Hiroshima University, Hiroshima, Japan \\ ${ }^{4}$ Twin Union of Mongolia, Ulaanbaatar, Mongolia \\ ${ }^{5}$ Department of Epidemiology, School of Public Health, Health Sciences University of Mongolia, Ulaanbaatar, Mongolia \\ ${ }^{6}$ Department of Medical Care Policy, Implementation and Coordinaiton, Ministry of Health, Ulaanbaatar, Mongolia \\ ${ }^{7}$ Department of Molecular Biology and Genetics, Health Sciences University of Mongolia, Ulaanbaatar, Mongolia \\ ${ }^{8}$ Department of Higher Education, Ministry of Education and Science, Ulaanbaatar, Mongolia \\ ${ }^{9}$ Healthy Twin Association of Mongolia, Ulaanbaatar, Mongolia \\ ${ }^{10}$ Complex Disease and Genome Epidemiology Branch, Department of Epidemiology, School of Public Health, Seoul \\ National University, Seoul, Korea
}

\begin{abstract}
Despite the need to provide evidence-based health policy, most developing countries suffer from a lack of resources for sound epidemiologic evidence. Most twin registers have been established in developed countries and there are relatively fewer twin registers in developing countries. Considering the immense potential of twin research, it will be worthwhile to attempt to establish a new twin register in Mongolia, where biomedical studies are still scarce. Our objectives were to initiate the process of establishing a nationwide twin register in Mongolia, based on a nation-wide, population-based database. With the approval and support of the Ministry of Population Development and Social Welfare of Mongolia, we were able to access an initial list of 411 twin pairs who live in the district of Ulaanbaatar, the capital city of Mongolia. By developing a questionnaire to estimate zygosity, we conducted a pilot survey. Those who registered consisted of 822 individuals or 411 twin pairs (same sex: male - 178; female - 157; different sex - 76), two sets of triplets (same sex: female - 2). The age of twins ranged from 1 to 81 (mean age 7.3 \pm 11.3 ), and $52.4 \%$ were males. The first twin survey in Mongolia not only resulted in interim data for the Mongolian Twin Register, but has the potential for establishing a larger register by using the national database. It has been proven possible to establish a twin register for research purposes in Mongolia.
\end{abstract}

Keywords: twin register, twin research

Nowadays, most twin research studies tend to be focused solely in the developed countries, despite some research on the subject from developing countries that is starting to emerge. Considering the value of investigation of genetic and environmental factors in complex traits, as well as the distribution and heritability of various phenotypes across different populations, the establishment of more national twin registries is quite important (Ohm \& Derom, 2006; Sung et al., 2002, 2006). As an iterative solution for research, the criteria for selection of twins and method of determination can be essential for twin registries using population-based approaches. The aim of the present article is to describe the methods we used to conduct this study, and to provide baseline results on the nature of the samples identified.

\section{Methods}

\section{Setting}

The Mongolian Twin Register is based in Songinokhairkhan, one of the nine districts of Ulaanbaatar, the capital city of Mongolia. In 2011, the population of Ulaanbaatar numbered 1.3 million people, which accounts for

RECEIVED 10 October 2012; ACCEPTED 26 October 2012. First published online 12 December 2012.

ADDRESS FOR CORRESPONDENCE: Narandalai Danshiitsoodol, Medical Faculty, Graduate School of Biomedical and Health Sciences, Hiroshima University Kasumi 1-2-3, Minami-ku, Hiroshima City, Hiroshima 734-8553, Japan. E-mail: naraa@hiroshima-u.ac.jp 
$50 \%$ of the total population of Mongolia. Each district is divided into khoroo, which is the smallest administrative unit in terms of population size (approximately 8,000 people in each). There are a total of 32 khoroos and 240,295 people in Songinokhairkhan, which accounts for $25 \%$ of total population of Ulaanbaatar.

\section{Participants}

Ascertainment of twins. We randomly selected nine khoroos from the Songinokhairkhan district. The municipal register in each khoroo of the capital contains information such as data on births, names, and deaths of all residents. Thus, these civil registration records were used to identify the source of participants for the twin register. The national registration data lacked the 8-digit individual identification number given to all Mongolians at birth, consisting of the date of birth (first 6 digits, year-month-day). Participants are sorted by last name, birth date, and home address. Persons born on the same day and same place, and given the same surname at birth, as well as living in the same home, are almost certainly twins.

\section{Pilot Study}

Randomly selected participants for a pilot study were identified and letters sent to those participants explaining the study in more detail. The participants were offered the right to refuse to participate. They were informed that interviews could take place in their own home or at the research center. Twins were excluded if the individuals said they were not twins; one or both of the pair had died or gone abroad; or there were no twins at the given address. Fieldworkers completed the interview (consisting of four pages, and lasting 20 minutes). A group of eight individuals (mostly students from a medical college) were extensively trained as field workers.

\section{Zygosity Determination}

We assessed zygosity using a questionnaire. Six questions to estimate zygosity were asked. Pairs where both twins reported a 'water drop-like resemblance', and schoolteachers or friends 'always or nearly always' had problems distinguishing between them were categorized as monozygotic (MZ). The pairs who did not report having a 'water droplike resemblance', and were 'seldom' or 'never' confused by teachers or friends were categorized as dizygotic (DZ). All remaining pairs, including those pairs whose zygosity categories conflicted, were assessed as uncertain zygosity.

\section{Anthropometric Measure and Heritability Estimation}

Birth weight, height, and weight were self-reported and body mass index was calculated as the ratio of weight $(\mathrm{kg})$ to height (in meters) squared. The twin birth rates were
TABLE 1

Total and Twin Live Births From 2001 to 2011: Mongolia

\begin{tabular}{|c|c|c|c|c|}
\hline \multirow[b]{2}{*}{ Birth year } & \multicolumn{2}{|c|}{ Live birth } & \multicolumn{2}{|c|}{ Twins } \\
\hline & $\begin{array}{l}\text { Total live } \\
\text { birth }\end{array}$ & $\begin{array}{l}\text { Sex ratio } \\
\text { (M to } F)\end{array}$ & Twin pairs & $\begin{array}{l}\text { Twin birth rate } \\
\text { (per } 1000 \text { live } \\
\text { birth) }\end{array}$ \\
\hline 2001 & 48,449 & 1.05 & 378 & 7.8 \\
\hline 2002 & 45,687 & 1.06 & 413 & 9.1 \\
\hline 2003 & 44,744 & 1.06 & 363 & 8.1 \\
\hline 2004 & 44,521 & 1.03 & 406 & 9.1 \\
\hline 2005 & 45,171 & 1.06 & 392 & 8.7 \\
\hline 2006 & 47,376 & 1.06 & 437 & 9.2 \\
\hline 2007 & 55,774 & 1.04 & 564 & 10.1 \\
\hline 2008 & 63,262 & 1.06 & 641 & 10.2 \\
\hline 2009 & 68,762 & 1.05 & 686 & 10.0 \\
\hline 2010 & 65,889 & 1.05 & 695 & 10.6 \\
\hline 2011 & 70,576 & 1.05 & 749 & 10.6 \\
\hline Total & 600,211 & 1.05 & 5,724 & 9.6 \\
\hline
\end{tabular}

Note: Total and twin live births from 2001 to 2011 were identified by using the annual report (The report of Health Indicators 2001-2011) of Ministry of Health, Mongolia.

The annual report is based on the birth records that include information on twins vs. singletons.

computed by dividing the number of twins by the total number of births and multiplying the outcome by 1000 .

\section{Results}

Total births and twin live births in Mongolia from 2001 to 2011 are shown in Table 1. A total of 600,211 births were recorded during this 11-year period. Of these, 11,448 were twin births. The 2001 twin birth rate was 7.8 per 1,000. This rose slightly in 2002, when the twin birth rate was 9.1 per 1,000 . The twinning rate rose sharply between 2006 and 2010 (from 9.2 to 10.6) and was fairly stable in 2011.

Those who registered comprise 822 individuals or 411 twin pairs (same sex: male -178 ; female -157 ; different sex - 76), 2 sets of triplets (same sex: female -2 ). The oldest twins and triplets are 81 and 16 years old, respectively; $79.8 \%$ of twins are less than 10 years old (Table 2). The mean age was $6.5 \pm 9.3$ years and $8.1 \pm 12.8$ years for men and women, respectively, and $52.4 \%$ were male. Interviews were performed on 77 twin pairs or 154 individuals. Those twins who were interviewed comprised 39 male pairs (18 pairs classified as MZ, 20 as DZ, and 1 as XZ) and 38 female pairs (22 pairs classified as MZ, 13 as DZ, and 3 as XZ; see Table 2). Mean observed anthropometric values are showed in Table 3. Heritability of height, weight, and birth weight as well as BMI was $0.98,0.84,0.45$, and 0.31 , respectively.

\section{Discussion}

We report the results of the pilot study for establishing twin registration in Mongolia. The rate of twin births rose sharply from 9.2 to 10.6 per 1,000 births in 2006 and 2010, respectively, and was quite stable in 2011. It is well documented that the twinning rate is much lower in Mongoloid people (Hur \& Song, 2009; Rushton, 1990) to that in other races 


\section{TABLE 2}

Age, Sex, and Zygosity Distribution of the Registered and Pilot Study Participants, Number of Pairs (for Twins)

\begin{tabular}{|c|c|c|c|c|c|c|c|c|c|c|c|c|c|c|c|c|}
\hline \multirow[b]{3}{*}{$\begin{array}{l}\text { Age } \\
\text { group }\end{array}$} & \multicolumn{3}{|c|}{ Registered twins } & \multicolumn{13}{|c|}{ Pilot Study Twins (number of pairs) } \\
\hline & \multirow[b]{2}{*}{ Male (\%) } & \multirow[b]{2}{*}{ Female (\%) } & \multirow[b]{2}{*}{ Total (\%) } & \multicolumn{3}{|c|}{ MZ* pairs } & \multicolumn{3}{|c|}{ DZ* pairs } & \multicolumn{3}{|c|}{$X Z \dagger$ pairs } & \multicolumn{3}{|c|}{ All } & \multirow[b]{2}{*}{$\begin{array}{l}\text { Response } \\
\text { rate (\%) }\end{array}$} \\
\hline & & & & Men & Women & $\begin{array}{l}\mathrm{MZ} \\
\text { sum }\end{array}$ & Men & Women & $\begin{array}{l}\text { DZ } \\
\text { sum }\end{array}$ & Men & Women & $\begin{array}{l}X Z \\
\text { sum }\end{array}$ & Men & Women & Total & \\
\hline $0-1$ & $94(21.8)$ & $116(29.6)$ & $210(25.5)$ & 3 & 1 & 4 & 3 & 2 & 5 & 0 & 0 & 0 & 6 & 3 & 9 & 4.3 \\
\hline $2-4$ & $190(44.1)$ & $138(35.3)$ & $328(39.9)$ & 5 & 1 & 6 & 3 & 2 & 5 & 0 & 1 & 1 & 8 & 4 & 12 & 3.6 \\
\hline $5-9$ & $59(13.6)$ & $41(10.9)$ & $100(12.1)$ & 4 & 3 & 7 & 5 & 1 & 6 & 0 & 1 & 1 & 9 & 5 & 14 & 14.0 \\
\hline 10-19 & $46(10.6)$ & $42(10.7)$ & $88(10.7)$ & 2 & 6 & 8 & 4 & 4 & 8 & 1 & 0 & 1 & 7 & 10 & 17 & 19.3 \\
\hline$>20$ & $42(9.7)$ & $54(13.8)$ & $96(11.6)$ & 4 & 11 & 15 & 5 & 4 & 9 & 0 & 1 & 1 & 9 & 16 & 25 & 26.0 \\
\hline Subtotal & $431(52.4)$ & $391(47.6)$ & $822(100)$ & 18 & 22 & 40 & 20 & 13 & 33 & 1 & 3 & 4 & 39 & 38 & 77 & 9.4 \\
\hline
\end{tabular}

Notes: $M Z$ = monozygotic twin; $\mathrm{DZ}=$ dizygotic twin; $\mathrm{XZ}=$ zygosity undetermined twin.

*Zygosity estimation was based on questionnaire.

$\nmid Z y g o s i t y$ of $X Z$ was assigned either in case questionnaire-based zygosity survey showed discrepancy between the cotwins (i.e., MZ vs. DZ) or both co-twins fell in the category of ambiguous zygosity.

\section{TABLE 3}

Heritability and Mean Observed Anthropometric Variables

\begin{tabular}{lllll}
\hline & & \multicolumn{3}{c}{ Age group (means $\pm S D$ ) } \\
\cline { 3 - 5 } Variables & Heritability & $0-9$ & $10-19$ & $>20$ \\
\hline Height & 0.98 & $90.7(20.6)$ & $152.3(15.3)$ & $166.1(10.2)$ \\
Weight & 0.84 & $16.4(5.8)$ & $46.1(11.9)$ & $64.8(14.4)$ \\
Birth weight & 0.45 & $2.6(5.2)$ & $2.5(3.0)$ & $2.4(5.2)$ \\
BMl & 0.31 & $20.6(8.7)$ & $19.6(3.2)$ & $23.4(4.2)$ \\
\hline
\end{tabular}

Note: $S D=$ standard deviation; $\mathrm{BMI}=$ body mass index.

(the highest twinning rates found across Central Africa are 18-30 twin sets per 1,000 live births, and twinning rates in the United States were reported as 31.4 per 1,000 in 2009; Fell \& Joseph, 2012). In detail, the twin birth rate of countries such as China and Vietnam is 9 twins per 1,000 births on average. There are also very low twin birth rates observed for Japan (7.8 per 1,000 in 2007; Kurosawa et al., 2011) and Singapore ( 7 per 1,000 in 2001; Chia et al., 2004). Compared with these twin birth rates, the twinning rate in Mongolia is rising and slightly higher.

In recent years, there have been various efforts made to improve civil registration and vital statistics systems in Mongolia. However, despite these efforts, there are still significant levels of under-registration, which can be traced back to the lack of awareness of its importance. Moreover, civil migration statistics are still inadequate or deficient in Mongolia. For this reason, we have attempted to identify twins from municipal record lists. The participants were sorted by last name, birth date, and home address. Persons born on the same day and at the same place, and given the same surname at birth as well as living in the same home were identified as twins. As for the issue of over-sampling of children younger than 10 years in our study, it should be noted that underage children living with their parents or legal guardians are considered as one household. This is how we have been able to easily identify underage twin participants. On the other hand, under-representation of adults in the twin register is because older twins are more likely to have moved away from one another. The method we have used in this study was successful for young twins, but not so for identifying older ones. With this in mind, one of the future aims of the twin register will be to make additional recruitment efforts within the general population, in order to increase the relative number of adolescent and adult twin participants to be comparable to the general population of Mongolia. To our knowledge, this is the very first study to have analyzed whether there is a potential as well as sufficient data for building a twin register in Mongolia.

\section{Conclusion}

We aimed to recruit twins within a defined population, and invited a random sample to participate in the study. It has proved possible to build a twin register for research purposes in Mongolia. The potential exists to create an important new resource for twin studies in Mongolia.

\section{Acknowledgments}

This study was supported by the National Research Foundation of Korea (NRF; No. 2011-220-E00006, and NRF 2012K2A1A2032536), and the Ministry of Population Development and Social Welfare of Mongolia.

\section{References}

Chia, K. S., Lee, J. J., Cheung, P., Cheung, K. H., Seielstad, M., Wilcox, M. M., \& Liu, E. (2004). Twin births in Singapore: A population-based study using the national birth registry. Annals of the Academy Medicine, Singapore, 33, 195-199.

Hur, Y. M., \& Song, T. B. (2009). A recent rise in twin birth rates and demographic changes in mothers of twins in South Korea: 2003-2007. Twin Research and Human Genetics. 12, $118-22$.

Kurosawa, K., Masuno, M., \& Kuroki, Y. (2012). Trends in occurrence of twin births in Japan. American Journal of Medical Genetics Part A 158A: 75-77. 
Ohm, K. K., \& Derom, C. (2006). Data collection on multiple births - Establishing twin registers and determining zygosity. Early Human Development, 82, 357-363.

Rushton, J. P. (1990). Race Differences and r/K Theory A Reply to Silverman. Ethology and Sociobiology, 11, 131-140.

Sung, J., Cho, S. H., Cho, S. I., Duffy, D. L., Kim, J. H., Kim, H., ... . Park, S. K. (2002). The Korean Twin
Registry-methods, current stage, and interim results. Twin Research, 5, 394-400.

Sung, J., Cho, S. I., Lee, K., Ha, M., Choi, E. Y., Choi, J. S., Kim, H., ... Song, Y. M. (2006). Healthy Twin: A twin-family study of Korea-protocols and current status. Twin Research and Human Genetics, 6, 844848. 